\title{
An experimental investigation on the post-cracking behaviour of Recycled Steel Fibre Reinforced Concrete
}

\author{
Cristina Frazão ${ }^{1}$, Joaquim Barros ${ }^{1}$, J. Alexandre Bogas ${ }^{2}$, Kypros Pilakoutas ${ }^{3}$ \\ 1: ISISE, University of Minho, Guimarães, Portugal. \\ 2: CERIS-ICIST, Instituto Superior Técnico, Technical University of Lisbon, Portugal. \\ 3. The University of Sheffield, United Kingdom.
}

\begin{abstract}
Steel fibres resulting from the industry of tyre recycling can be efficiently employed for the reinforcement of concrete structures. Recycled Steel Fibre Reinforced Concrete (RSFRC) is a promising candidate with technical, environmental and economic benefits for the development of ductile, high strength and durable constructive systems, as it is required for breakwater elements used on the protection of coastal zones.

For assessing the potentialities of recycled steel fibres (RSF) as concrete reinforcement, an experimental program was performed in the present work by comparing the following properties of concrete reinforced with industrial steel fibres (ISF) and with RSF: compressive strength, modulus of elasticity, flexural strength, flexural toughness and indirect tensile strength.

Under chloride attack, the durability performance of RSFRC requires the assessment of its corrosion resistance. To evaluate the corrosion effects on the post-cracking response of RSFRC, double edge wedge splitting tensile tests were conducted in RSFRC specimens previously exposed to aggressive chloride environment.

The obtained results demonstrate that, for the adopted industrial and recycled fibres, the last ones had not inferior post-cracking strengthening performance than the first ones. The corrosion action caused a slight decrease of the average post-cracking tensile strength of the RSFRC. The small percentage of rubber attached to RSF surface had a negligible effect in the corrosion resistance of RSFRC.
\end{abstract}

\section{Keywords}

Recycled steel fibres, industrial steel fibres, RSFRC, post-cracking behaviour, corrosion. 


\section{Introduction}

In a world that is becoming increasingly sensitive to the need of protecting the environment, the ability to build concrete structures using sustainable resources is an exciting and attractive proposition with environmental and economic benefits.

Nowadays, pneumatic tyres are among the most widespread industrial products and, giving the best use to tyres that have reached their end-of-life is still a societal challenge. In recent years, several efforts have been done for using different by-products obtained from the recycling of waste tyres, such is the case of deriving constituents for the concrete industry (Pilakoutas et al. 2004, Tlemat et al. 2003, Micelli et al. 2014, Zamanzadeh et al. 2015, Caggiano et al. 2017).

Steel fibres resulting from the industry of tyre recycling have high potential as an effective reinforcement of concrete, especially in terms of improving its post-cracking tensile behaviour, and increase its flexural, shear and impact strength (Pilakoutas et al. 2004, Tlemat et al. 2003, Micelli et al. 2014, Zamanzadeh et al. 2015, Caggiano et al. 2017). The heterogeneity of this fibre system (with regard to the geometry, composition and microstructure of each fibre) provides a plurality of strengthening mechanisms that can be an advantage, as long as these mechanisms are effectively activated, which requires scientific methodologies on the production of Recycled Steel Fibre Reinforced Concrete (RSFRC) and its application.

In coastal protection engineering, distinct structural systems of prefabricated plain concrete blocks are used in the construction of breakwaters to increase the dissipation and absorption of wave energy. Cracking is a common pathology in this type of structural systems that cause a significant (or complete) loss of their effectiveness. In this case, discrete fibres are considered ideal candidates for the reinforcement of this type of massive concrete elements, since the randomly nature of their distribution provides an almost isotropic reinforcement.

In this context, this study reports the results of an experimental research carried out at the University of Minho (Portugal) that aims to investigate the post-cracking behaviour of RSFRC and perform its comparison to the one registered in Industrial Steel Fibre Reinforced Concrete (ISFRC), by performing 3-point bending tests, round panel tests and double edge wedge splitting tests (DEWST). The corrosion effects on the post-cracking response of RSFRC previously subjected to chloride attack were also analysed from DEWST. The methodologies adopted and the experimental results are presented and discussed.

\section{Experimental program}

\subsection{Materials and mix compositions}

The recycled steel fibres (RSF) used in this research were recovered by a shredding process of post-consumed truck tires, being the steel separated from the rubber by an electromagnetic separator. These RSF have irregular geometry with various lengths and diameters (Fig. 1a). According to the data provided by the supplier, on average, the RSF had $20 \mathrm{~mm}$ in length $\left(l_{f}\right)$ and $0.15 \mathrm{~mm}$ in diameter $\left(d_{f}\right)$, for an aspect ratio $\left(l_{f} / d_{f}\right)$ of 133 , and 
tensile strength as high as $2850 \mathrm{MPa}$. For comparison purposes, hooked ends steel fibres of $l_{f}=33 \mathrm{~mm}, d_{f}=0.55 \mathrm{~mm}, l_{f} / d_{f}=60$, and yield stress of $1230 \mathrm{MPa}$ were also used (Fig. 1b).

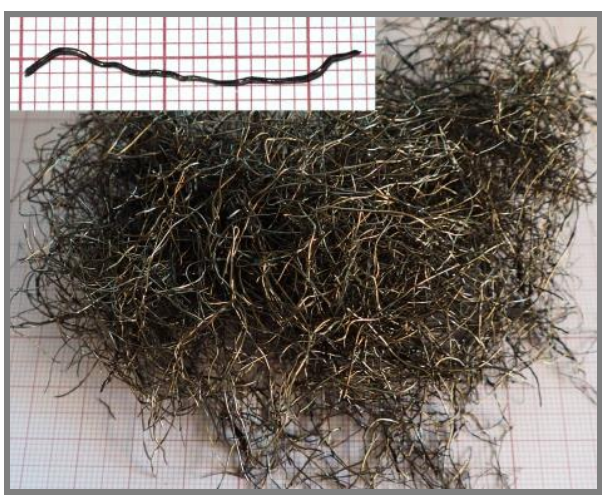

(a)

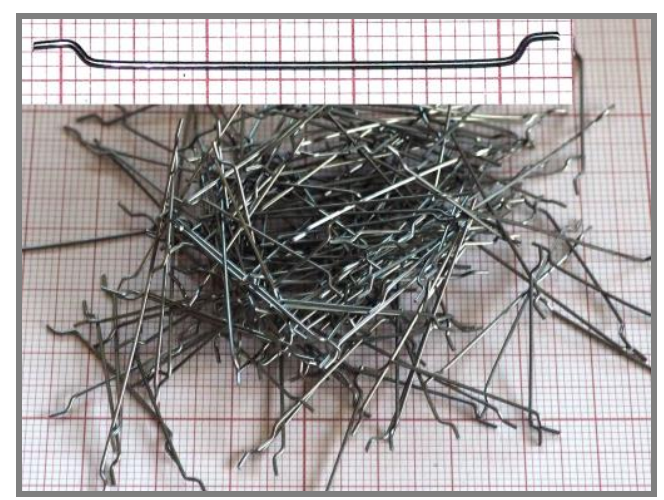

b)

Figure 1 - General view of multi fibres and the geometry of a single fibre:

(a) Recycled Steel Fibres: (b) Industrial Steel Fibres

RSFRC and ISFRC of equal composition were produced with 1\% of fibres (by volume of concrete, $\mathrm{V}_{\mathrm{f}}$ ), CEM I $42.5 \mathrm{R}$ Portland cement (C), fly ash (FA), fine river sand (FS) (maximum aggregate size of $1.19 \mathrm{~mm}$ and fineness modulus of 1.91), coarse river sand (CS) (maximum aggregate size of $4.76 \mathrm{~mm}$ and fineness modulus of 3.84) and crushed granite (CA) (maximum aggregate size of $19.10 \mathrm{~mm}$ and fineness modulus of 6.64), water (W) and a polycarboxylate based superplasticizer (SP) with the commercial designation MasterGlenium SKY 617. The mix design was based on the packing density optimization method suggested in Barros et al. (2007). For comparison purposes, specimens of plain concrete (PC) were also produced before the addition of $\mathrm{V}_{\mathrm{f}}=1 \%$ of $\mathrm{RSF}$.

To assess the corrosion effects on the post-cracking behaviour of RSFRC, concrete with a RSF content of $\mathrm{V}_{\mathrm{f}}=0.79 \%$ (Table 1) was produced using the composition proposed in Zamanzadeh et al. (2015), based on an experimental aggregate packing method for fibre reinforced concrete. This composition includes limestone filler (LF) instead of fly ash.

Table 1: Compositions for $1 \mathrm{~m}^{3}$ of concrete $\left(C_{f}=\right.$ content of fibres in $\left.\mathrm{kg} / \mathrm{m}^{3}\right)$

\begin{tabular}{|c|c|c|c|c|c|c|c|c|c|c|}
\hline Concrete & $\mathbf{C}(\mathbf{k g})$ & $\mathbf{F A}(\mathbf{k g})$ & $\mathbf{L F}(\mathbf{k g})$ & $\mathbf{F S}(\mathbf{k g})$ & $\mathbf{C S}(\mathbf{k g})$ & $\mathbf{C A}(\mathbf{k g})$ & $\mathbf{W}(\mathbf{L})$ & $\mathbf{S P}(\mathbf{L})$ & $\mathbf{C}_{\mathbf{f}}(\mathbf{k g})$ & $\mathbf{W} / \mathbf{C}$ \\
\hline $\begin{array}{c}\text { RSFRC1\% } \\
\text { ISFRC1\% }\end{array}$ & 400 & 200 & - & 147 & 735 & 597 & 173 & 7.2 & 75.8 & 0.31 \\
\hline RSFRC0.79\% & 381 & - & 353 & 237 & 710 & 590 & 140 & 7.8 & 60.0 & 0.37 \\
\hline
\end{tabular}

The workability of fresh plain concrete, RSFRC1\% and ISFRC1\% was determined by the Abrams slump-flow test according to the recommendation of EN 12350-8 (2010). The average slump was $250 \mathrm{~mm}$ for plain concrete, $100 \mathrm{~mm}$ for RSFRC1\% and $130 \mathrm{~mm}$ for ISFRC1\%, which is within the consistency Class S5 for plain concrete and Class S3 for RSFRC and ISFRC, according to the EN 206-1 (2007). As expected, adding fibres to fresh concrete results in a loss of workability, but the alterations on the mix composition for the production of RSFRC1\%, according to the adopted method, have assured the same consistency class of ISFRC1\%.

The compressive strength of these concretes were determined at 28 days in cylinders of $150 \mathrm{~mm}$ diameter and $300 \mathrm{~mm}$ height according to the EN 12390-3 (2009) and EN 12390-13 
(2012), respectively. The average values of compressive strength $\left(f_{c m}\right)$ and Young's modulus $\left(E_{c m}\right)$ are presented in Table 2.

Table 2: Relevant results of compressive tests

\begin{tabular}{|c|c|c|c|}
\cline { 2 - 4 } \multicolumn{1}{c|}{} & PC & RSFRC & ISFRC \\
\hline $\boldsymbol{E}_{\boldsymbol{c} \boldsymbol{c}}(\mathrm{MPa})(\mathbf{C o V} \%)$ & $25.76(3.49)$ & $24.31(10.04)$ & $26.80(3.11)$ \\
\hline $\boldsymbol{f}_{\boldsymbol{c} \boldsymbol{m}}(\mathbf{M P a})(\mathbf{C o V} \%)$ & $43.45(4.12)$ & $39.42(3.72)$ & $48.87(2.43)$ \\
\hline
\end{tabular}

A slight decrease of compressive strength and modulus of elasticity was observed in RSFRC comparing with the control mix (PC). This may have been caused by the relatively high number of fibres and their heterogeneous geometry in the RSFRC that increase the volume of the interfacial transition zone (ITZ) between fibre and matrix, and may also have increased the void percentage in the matrix. In addition, RSFRC was produced with significantly lower slump, which affects the homogeneity and air content of concrete. However, in the case of ISFRC of similar slump, the opposite occurred, and a slight increase of the compressive strength and the modulus of elasticity was observed.

\subsection{Post-cracking behaviour of RSFRC}

The post-cracking behaviour of RSFRC1\% and ISFRC1\% was analysed using different test methods, namely, 3-point bending tests, round panel tests and splitting tensile tests.

\subsubsection{Three-point notched beam bending tests (3PNBBT)}

The flexural behaviour of PC, RSFRC1\% and ISFRC1\% was characterized by executing three point notched beam bending tests (3PNBBT) according to the CEB-FIP Model Code recommendations (2013) in terms of curing procedures, position and dimensions of the notch sawn into the specimen, load and specimen support conditions, main characteristics of the equipment and measuring devices, and test procedure (Fig. 2).

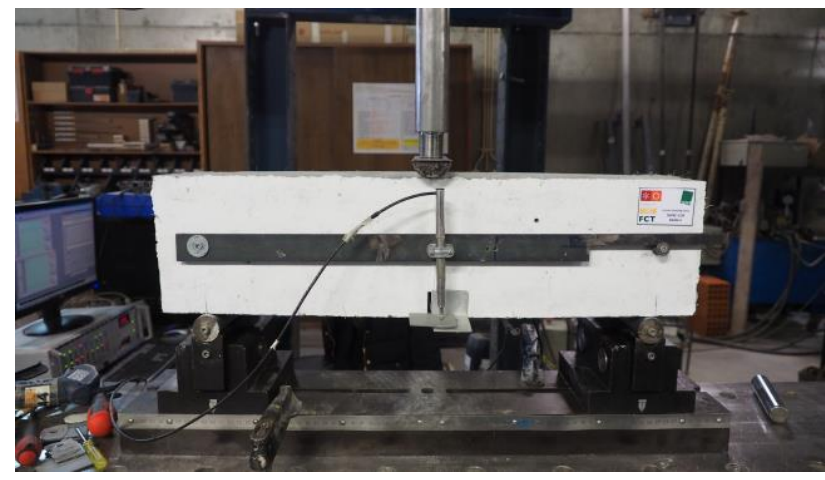

Figure 2 - Test setup of the bending test

Figure 3 represents the average force-deflection (F-u) and force-CMOD responses registered in the PC, RSFRC and ISFRC at 28 days. 


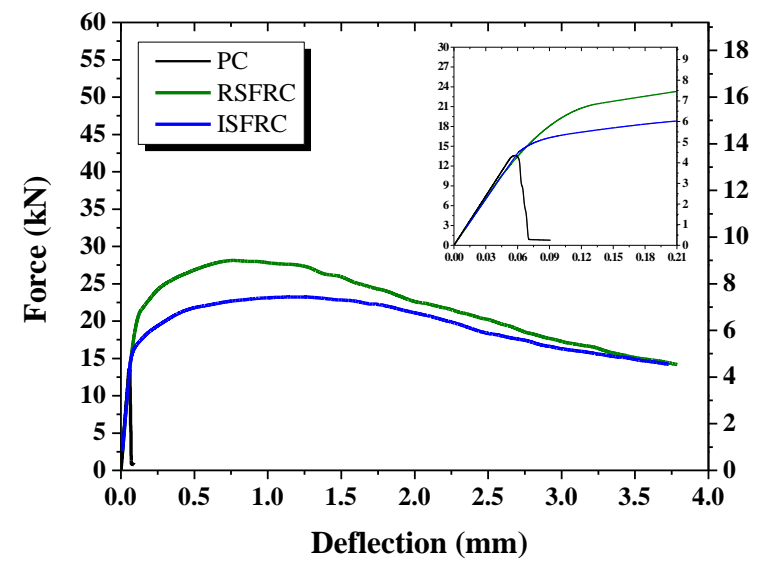

(a)

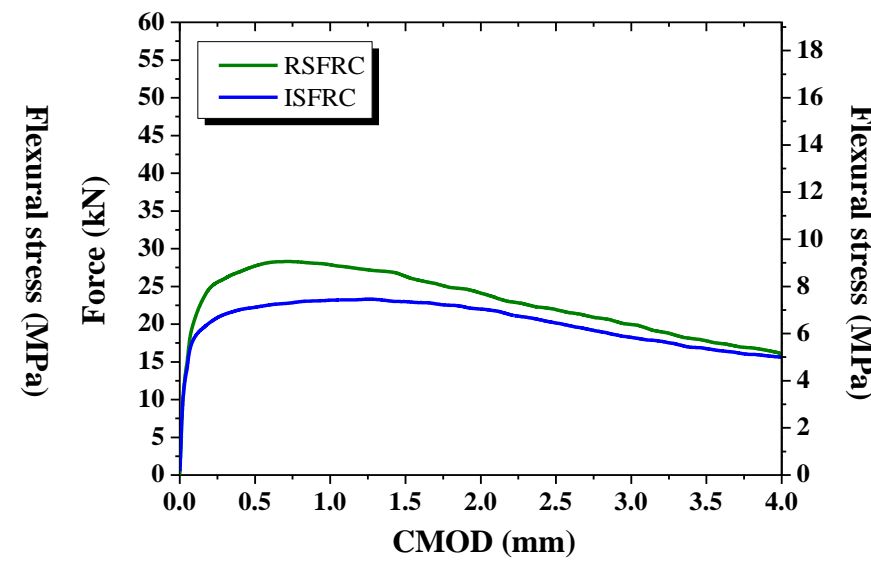

(b)

Figure 3 - (a) Average force/flexural stress versus deflection, and (b) Average forcelflexural stress versus crack width for specimens of PC, RSFRC and ISFRC

The average values and corresponding coefficients of variation of the flexural tensile strength, $f_{c t m, f l}$, and the energy absorbed up to a deflection of $3.5 \mathrm{~mm}, \boldsymbol{G}_{f m}$, which represents the area under the F-u curves (Fig. 3a) up to this deflection, were $4.43 \mathrm{MPa}(6.27 \%)$ and 0.07 $\mathrm{N} / \mathrm{mm}(0.77 \%)$ for PC, $9.11 \mathrm{MPa}(8.87 \%)$ and $4.25 \mathrm{~N} / \mathrm{mm}(11.67 \%)$ for RSFRC1\% and 7.66 MPa $(8.17 \%)$ and $3.13 \mathrm{~N} / \mathrm{mm}(10.87 \%)$ for ISFRC1\%. Up to a deflection of about $3.5 \mathrm{~mm}$, the RSFRC1\% has presented higher flexural capacity and energy absorption performance than ISFRC. The highest difference has occurred for crack width levels corresponding to serviceability limit state (SLS) conditions. The reinforcement performance of both FRCs has become closer with the increase of the crack width, which indicates that they will have similar performance for ultimate limit state (ULS) conditions.

From the obtained force-CMOD relationship (Fig. 3b), the residual flexural tensile strength parameters $\left(f_{R, 1}, f_{R, 2}, f_{R, 3}\right.$ and $\left.f_{R, 4}\right)$ were calculated according to CEB-FIP Model Code recommendations (2013). The obtained results are presented in Table 3 and confirmed the higher effectiveness of RSF comparing with ISF in terms of bending behaviour.

Table 3: Relevant results of flexural tests

\begin{tabular}{|c|c|c|c|c|c|}
\cline { 3 - 6 } \multicolumn{2}{c|}{} & $\begin{array}{c}f_{R, 1} \\
(\mathbf{M P a})\end{array}$ & $\begin{array}{c}f_{R, 2} \\
(\mathbf{M P a})\end{array}$ & $\begin{array}{c}f_{R, 3} \\
(\mathbf{M P a})\end{array}$ & $\begin{array}{c}f_{R, 4} \\
(\mathbf{M P a})\end{array}$ \\
\hline \multirow{2}{*}{ RSFRC1\% } & $\mathrm{AVG}$ & 8.87 & 8.41 & 7.02 & 5.72 \\
\cline { 2 - 6 } & $\operatorname{CoV}(\%)$ & 6.78 & 11.87 & 13.74 & 14.27 \\
\hline \multirow{2}{*}{ ISFRC1\% } & $\mathrm{AVG}$ & 7.12 & 7.39 & 6.58 & 5.42 \\
\cline { 2 - 6 } & $\operatorname{CoV}(\%)$ & 6.51 & 10.36 & 13.99 & 13.86 \\
\hline
\end{tabular}

\subsubsection{Round Panel tests}

To characterize the flexural toughness of RSFRC1\% and ISFRC1\%, round panel tests with three-point supports (RPT-3ps) were carried out according to the recommendations of ASTM C1550 (2005). In order to facilitate handling and placing the specimens, the RPT-3ps were conducted on smaller round panels with $600 \mathrm{~mm}$ diameter and $60 \mathrm{~mm}$ thickness, simply supported on three pivots with the symmetrical arrangement at 120 degrees, and 
subjected to a central load (Fig. 4). According to Minelli and Plizzari (2010), such a reduction of the panel's diameter and thickness does not affect the scatter and repeatability of the test results when compared to the standard specimens of ASTM C1550 (2005). The RPT3 ps tests were performed in displacement control by imposing a deflection rate of $4 \mathrm{~mm} / \mathrm{min}$ at the center of the panel up to a central displacement of at least $45.0 \mathrm{~mm}$.

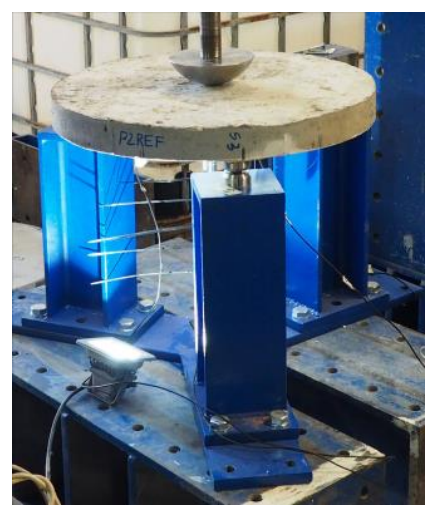

(a)

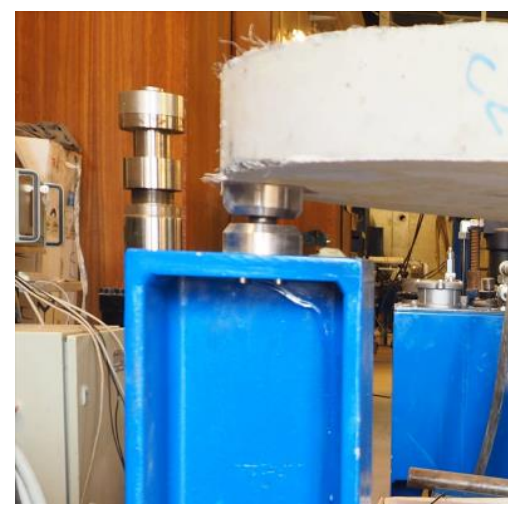

(b)

Figure 4-Round panel test: (a) Test setup, (b) One of the three pivots of the supporting system for $R P T$

In Figure 5 are depicted the average force-central deflection and energy absorption-central deflection relationships of RSFRC1\% and ISFRC1\% Panels. The crack failure pattern of each round panel was formed by three cracks at angles of about $120^{\circ}$, with the panel breaking into 3 pie-shaped wedges at large deflections. Like what was observed in the 3PNBBT, the RSFRC1\% has also provided higher flexural capacity and energy absorption performance than ISFRC1\% in the RPT. The higher aspect ratio and number of RSF can justify this better performance of RSFRC1\% (Micelli et al., 2014).

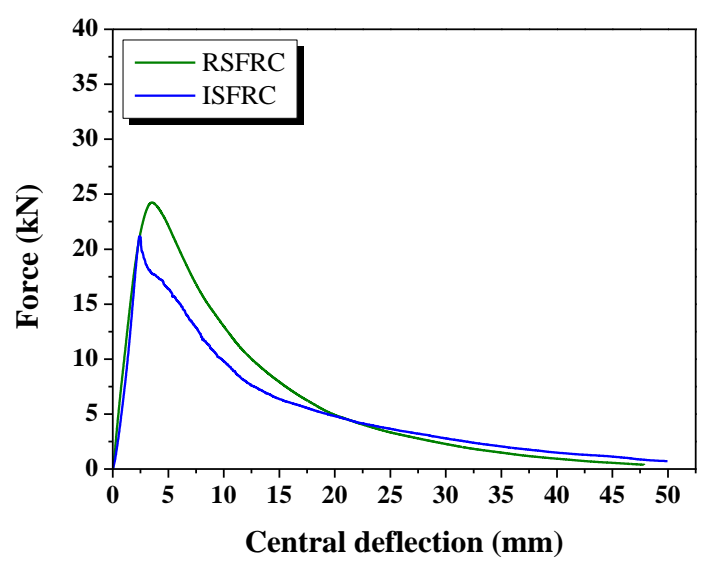

(a)

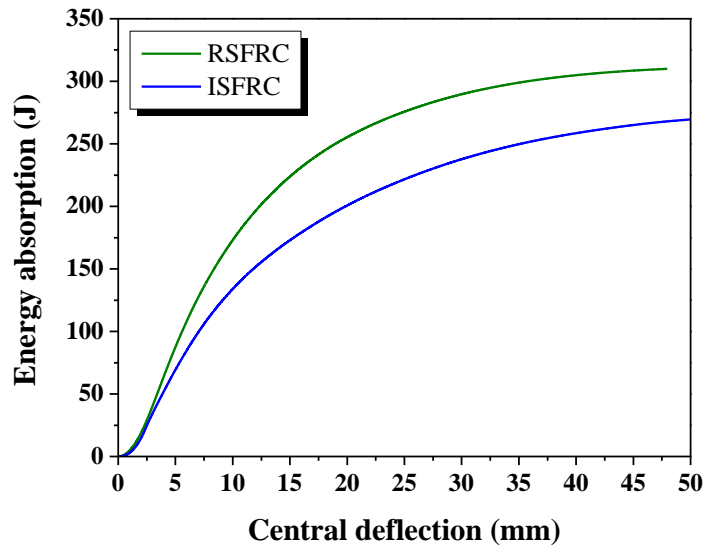

(b)

Figure 5 - (a) Average force versus central deflection, and (b) Average energy absorption versus central deflection of RSFRC1\% and ISFRC1\% panels

\subsubsection{Splitting tensile tests}

Double edge wedge splitting tests (DEWST) were performed on four cylindrical specimens with $\phi 150 \times 60 \mathrm{~mm}$ obtained by cutting from moulded $\phi 150 \times 300 \mathrm{~mm}$ specimens, as shown in Fig. 6. 
In each specimen, $5 \mathrm{~mm}$ deep notches were executed parallel to the loading direction, in order to set the specimen's fracture surface along the notched plane (notch 2 in Fig. 6a). Following the procedure adopted by di Prisco et al. (2013), a V-shaped groove with $45^{\circ}$ inclination was also executed at the ends of the notched plane, as illustrated in Fig. 6a (notch 1). The objective of this $\mathrm{V}$-shaped groove was to induce a stress field corresponding to an almost pure mode I fracture in the notched plane.

The splitting tests were conducted under displacement control using an external LVDT that was positioned on the actuator to control the vertical deformation of the specimen. The following displacement rates were adopted: $1.0 \mu \mathrm{m} / \mathrm{s}$ up to the displacement of 2.0 $\mathrm{mm} ; 2.0 \mu \mathrm{m} / \mathrm{s}$ from $2.0 \mathrm{~mm}$ up to $3.0 \mathrm{~mm} ; 4.0 \mu \mathrm{m} / \mathrm{s}$ until the end of the test. For an accurate detection and tracking of the crack propagation, five LVDTs were used to measure the crack opening displacement along the fracture surface (Fig. 6b), three on the front face and two on the rear face of the specimen. The DEWST were carried out according with a new test method (Lameiras et al., 2015) that results from the combination of the methodology proposed by di Prisco et al. (2013) for indirect evaluation of the mode I fracture properties of fibre reinforced concrete (FRC) and the Modified Splitting Tensile Test (MSTT) introduced by a group of researchers from the University of Minho (Abrishambaf et al., 2013, 2015), which tried to overcome the limitations of each test method, deviating the crosswise compressive stresses from the fractured section while a unique fracture plane is likely to be obtained.
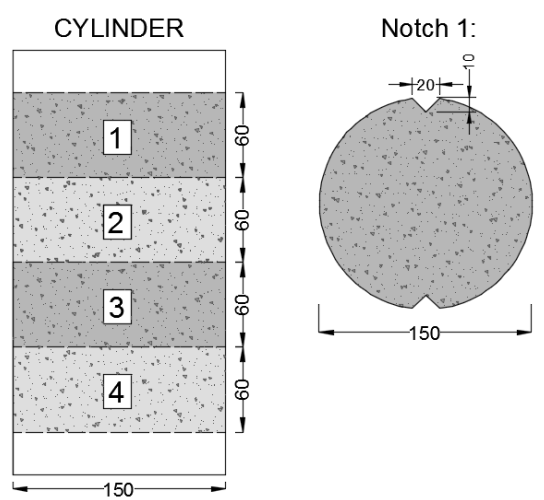

(a)

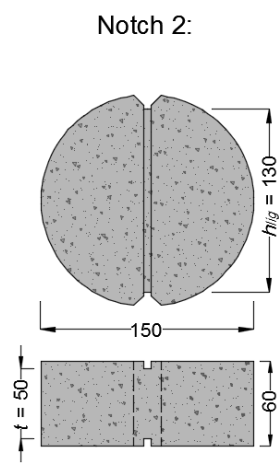

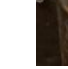

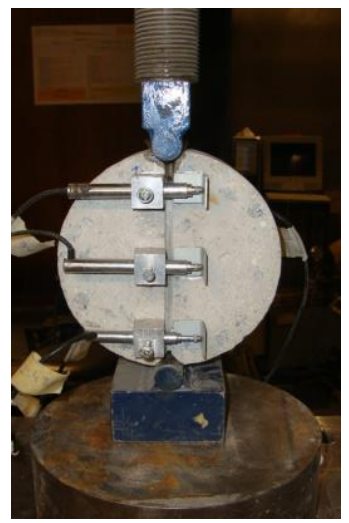

(b)

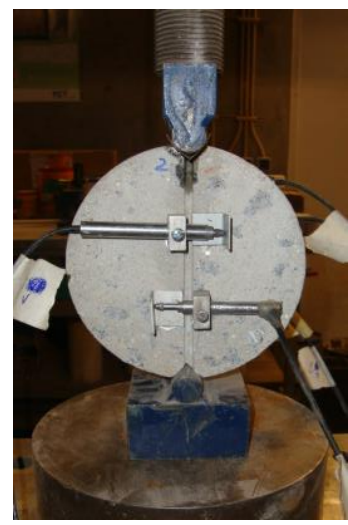

(c)

Figure 6-(a) Cutting of cylinders in $\phi 150 \times 60 \mathrm{~mm}$ specimens and implementation of the respective specimen's notches (units in millimeters);(b) Test setup for splitting tensile tests - Specimen front view; (c) Specimen back view

Figure 7 shows the average splitting tensile stress $\left(\sigma_{t, s p l i t}\right)$ versus crack width curves for RSFRC1\% and ISFRC1\%, where $\sigma_{t, \text { split }}$ was determined from the following equation, as proposed by di Prisco et al. (2013):

$$
\sigma_{t, s p l i t}=\frac{0.89 \cdot P}{t \cdot h_{l i g}}
$$

where $P$ is the compressive load, and $t$ and $h_{\text {lig }}$ are the thickness and the effective length of the notched region that defines the plan of failure, respectively. The crack width in X-axes corresponds to the average values measured by the five LVDTs during the loading stage of the specimens (Fig. 6b and 6c). 


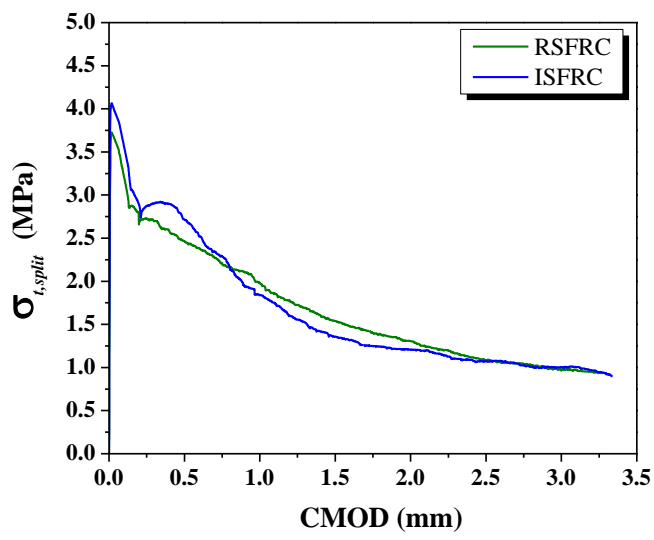

Figure 7 - (a) Average splitting tensile stress versus crack width for specimens of RSFRC1\% and ISFRC1\%

According to Fig. 7, RSFRC1\% showed similar values of indirect tensile strength and postcracking behaviour to the ones registered in ISFRC1\%. These results do not corroborate the results obtained in 2.2.1 and 2.2.2, which may be attributed to the differences between the tests setup, particularly with regard to the crack opening process, which is more constant in DWEST than in 3PNBBT and RPT-3ps, being different the activated reinforcement mechanisms.

\subsection{Post-cracking behaviour of RSFRC under corrosion action}

After 28 days of curing, 4\$150x60 mm specimens of RSFRC were immersed during 10 days in $3.5 \%$ wt. $\mathrm{NaCl}$ solution in order to induce fibre corrosion. For comparison purposes, also 4 reference specimens were cured in water, without corrosion induction.

The majority of RSF used in this research still contained some attached rubber debris in their surface. The influence of these small rubber debris was also analyzed by using two distinct pre-treatment methods to remove them: pre-treatment of fibres at $350^{\circ} \mathrm{C}$, and manual polishing. According to this, the following three classes of RSF were considered in these splitting tensile tests: Class 1 - Reference RSF, without pretreatment, as were received; Class 2 - RSF pre-treated at $350^{\circ} \mathrm{C}$; Class 3 - Polished RSF.

Figure 8 shows the average splitting tensile stress $\left(\sigma_{t, s p l i t}\right)$ versus crack width curves determined according to equation (1) for specimens with RSF of class 1, 2, and 3, as described in 2.3 .

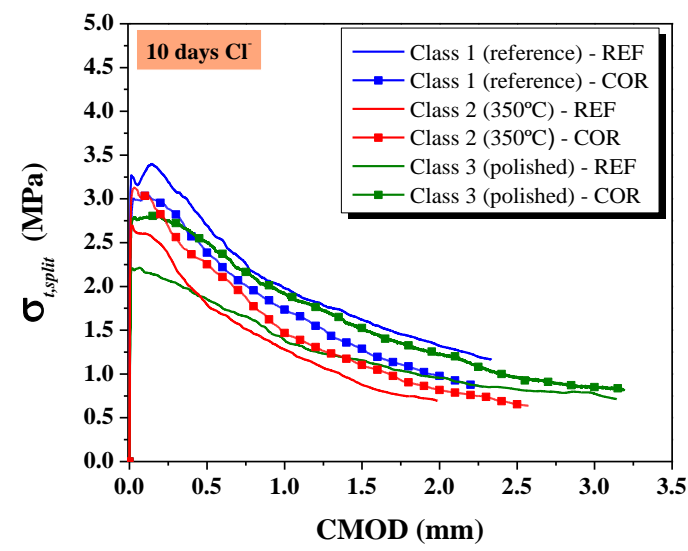

Figure 8-Average splitting tensile stress versus crack width for specimens with RSF of class 1, 2 and 3, not exposed to $\mathrm{NaCl}$ solution (REF) or under corrosion action (COR) 
The reference specimens of class 1 RSF showed the highest average stress at crack initiation (3.27 MPa) and the highest average post-cracking tensile strength (3.40 $\mathrm{MPa})$, which means that the two methods used to remove the small percentage of rubber from the fibres surface have decreased the splitting tensile strength of RSFRC (Fig. 8). This means that the pull-out strength of RSF was affected by the cleaning treatment of their surface.

For specimens of class 1 RSF (without surface treatment), the corrosion action caused a slight decrease of the average stress at crack initiation (7.9\%) and the average of the maximum post-cracking tensile strength $(10.3 \%)$. However, for RSF of class 2 (fibres subjected at $350^{\circ} \mathrm{C}$ ) and 3 (polished surface), the corrosion action led to the increase of the average stress at crack initiation (16.2\% in class 2 and $26.2 \%$ in class 3$)$. This suggests that the corrosion products may have promoted a greater surface roughness of class 2 and $3 \mathrm{RSF}$, which increased their pull-out strength. On the other hand, class 1 RSF with an original rougher surface was negatively affected by the steel fibre corrosion.

Nevertheless, all the RSFRC specimens submitted to chloride immersion showed similar post-cracking behaviour, which means that the small percentage of rubber attached to fibres surface has a negligible effect in the corrosion resistance of RSFRC.

\section{Concluding remarks}

The experimental findings presented in the present paper allows to point out the following observations:

1. RSF caused a slight reduction of the compressive strength of concrete.

2. From 3-point notched beam bending tests and round panel tests, RSFRC exhibited higher flexural strength and energy absorption capacity than ISFRC of equal composition.

3. No significant differences were observed between the post-cracking tensile behaviour of RSFRC and ISFRC in double edge wedge splitting tests.

4. The methods implemented to remove the small percentage of rubber from the fibres surface have decreased the splitting tensile strength of RSFRC.

5. After 10 days of chloride immersion, a slight decrease of the average post-cracking tensile strength was observed in the concrete specimens reinforced with reference RSF (as were received). However, treated RSF showed greater efficiency after corrosion.

6. All the RSFRC specimens submitted to chloride immersion showed similar postcracking behaviour, which means that the small percentage of rubber attached to fibres surface has a negligible effect in the corrosion resistance of RSFRC, as well as in the bond performance of RSF.

\section{Acknowledgements}

The authors wish to acknowledge the support from FCT through PTDC/ECMEST/2635/2014 project, as well as the collaboration of CiviTest Company in the production of concretes. The first author would like to thank the FCT for the financial support through the Research Grant PD/BD/113638/2015. The supplying of RSF and ISF from Twincon and Maccaferri Companies, respectively, is also acknowledged. 


\section{References}

Pilakoutas K., Neocleous K., Tlemat H. (2004). Reuse of tyre steel fibres as concrete reinforcement. Proceedings of the ICE: Engineering Sustainability, 157(3), 131-138.

Tlemat H., Pilakoutas K., Neocleous K. (2003). Flexural toughness of SFRC made with fibres extracted from tyres. Recycling and Reuse of Waste Materials, Proceedings of International Symposium on Advances in Waste Management and Recycling, Dundee, 9-11 September 2003, Pub. Thomas Telford Ltd.

Micelli F., Leone M., Centonze G., Aiello M. (2014). Chapter: Go Green: Using Waste and Recycling Materials, Infrastructure Corrosion and Durability Sustainability Study, Edited by Yang Lu, OMICS Group eBooks, USA.

Zamanzadeh Z., Lourenço L.A.P., Barros J.A.O. (2015). Recycled Steel Fibre Reinforced Concrete failing in bending and in shear. Construction and Building Materials, 85, 195 207.

Caggiano A., Folino P., Lima C., Martinelli E., Pepe M. (2017). On the mechanical response of Hybrid Fiber Reinforced Concrete with Recycled and Industrial Steel Fibers. Construction and Building Materials, 147, 286-295.

Barros J., Pereira E., Santos S. (2007). Lightweight panels of steel fibre reinforced selfcompacting concrete. Journal of Materials in Civil Engineering, 19(4), 295-304.

EN 12350-8 (2010). Testing fresh concrete - Part 8: Self-Compacting Concrete - Slump-flow test.

NP EN 206-1 (2007). Concrete - Part 1: Specification, performance, production and conformity. IPQ, Lisbon, pp. 21.

EN 12390-3 (2009). Testing hardened concrete - Part 3: Compressive strength of specimens.

EN 12390-13 (2012). Testing hardened concrete - Part 13: Determination of secant modulus of elasticity in compression.

CEB-FIP Model Code 2010 - Volume 1. Tomas Telford, Lausanne, Switzerland, 2013.

ASTM C1550-05 (2005). Standard test method for flexural toughness of fiber reinforced concrete (using centrally loaded round panel). ASTM International.

Minelli, F. and Plizzari, G.A. (2010). Fiber reinforced concrete characterization through round panel test - part $i$ : Experimental study. In: B.H.O.e. al. (editor). Fracture Mechanics of Concrete and Concrete Structures - High Performance, Fiber Reinforced Concrete, Special Loadings and Structural Applications, pages. Seoul, Korea.

di Prisco M., Ferrara L., Lamperti M.L. (2013). Double edge wedge splitting (DEWS): an indirect tension test to identify post-cracking behaviour of fibre reinforced cementitious composites. Materials and Structures, 46 (11), 1893-1918.

Lameiras R., Barros J., Azenha M. (2015). Influence of casting condition on the anisotropy of the fracture properties of Steel Fibre Reinforced Self-Compacting Concrete (SFRSCC). Cement \& Concrete Composites, 59, 60-76.

Abrishambaf A., Barros J.A.O., Cunha V.M.C.F. (2015). Tensile stress-crack width law for steel fibre reinforced self-compacting concrete obtained from indirect (splitting) tensile tests. Cement \& Concrete Composites, 57, 153-165.

Abrishambaf A., Barros J.A.O., Cunha V.M.C.F. (2013). Relation between fibre distribution and post-cracking behaviour in steel fibre reinforced self-compacting concrete panels. Cement and Concrete Research, 51, 57-66. 